\title{
Achieving Universal Health Coverage by 2030: The Role of Parliaments in Ensuring the Right to Health
}

\author{
Millat MH \\ Bangladesh Parliament, Dhaka, Bangladesh
}

In October 2018, on behalf of the Bangladesh Parliament, I proposed to the $139^{\text {th }}$ Assembly of the Inter Parliamentary Union (IPU) to adopt a resolution on "Achieving universal health coverage by 2030: The role of parliaments in ensuring the right to health" (Annex-1). After the acceptance of my proposal, I worked as a corapporteur along with Mr. Christian Lohr, Member of the National Council, Switzerland and Ms. Mariana Carvalho, Member of the Chamber of Deputies, Brazil for a year to consult with and gather inputs from the parliaments and parliamentarians across the world.

After several intensive discussions, debates and consultations in different parts of the world, we presented a draft proposal to the IPU member parliaments before presented it to the IPU assembly. Later, following the final debate and discussion, $141^{\text {st }}$ IPU assembly 2019 in Belgrade, Serbia approved this resolution. I believe this global tool will enable parliaments and parliamentarians to contribute in ensuring the highest attainable standard of health and global health targets by 2030 .

I am grateful to the Hon'ble Prime Minister of Bangladesh Jononetry Sheikh Hasina MP and the Hon'ble Speaker of Bangladesh Parliament Dr. Shirin Sharmin Chaudhury MP for their encouragement. I am also thankful to IPU President Ms Gabriela Cuevas Barron, IPU Secretary General Mr Martin Chungong and World Health Organization Director General Dr Tedros Adhanom Ghebreyesus for their regular guidance towards this initiative. My sincere appreciation goes to the colleagues from the Bangladesh Parliament, Ministry of Health and Family Welfare of Bangladesh, Ministry of Foreign Affairs of Bangladesh, IPU Secretariat and WHO Secretariat for their contribution in the process.

I hope our parliaments and parliamentarians will take full advantage of this resolution in their work to make the right decisions when it's come to those health issues.

I am now looking forward to working together with my fellow parliamentarians from home and abroad to deliver the commitment we have made through the IPU resolution on universal health coverage. I would appreciate your comment, suggestion and advice in this regard.

\author{
Correspondence: \\ Prof. Dr. Md. Habibe Millat \\ Member of Parliament \\ Bangladesh Parliament, Dhaka, Bangladesh \\ and \\ Initiator and leading co-rapporteur \\ IPU Resolution on the Universal Health Coverage \\ e-mail:profmhmillat@gmail.com
}


Annex-1

\title{
Achieving universal health coverage by 2030: The role of parliaments in ensuring the right to health
}

\author{
Resolution adopted by consensus ${ }^{1}$ by the $141^{\text {st }}$ IPU Assembly \\ Belgrade, 17 October 2019 \\ Co-Rapporteurs \\ Prof. Dr. Md. Habibe Millat MP (Bangladesh) \\ Mr. Christian Lohr MP (Switzerland) \\ Ms. Mariana Carvalho MP (Brazil)
}

The $141^{\text {st }}$ Assembly of the Inter-Parliamentary Union,

Recalling that, as affirmed in the Constitution of the World Health Organization (WHO), "the enjoyment of the highest attainable standard of health is one of the fundamental rights of every human being without distinction of race, religion, political belief, economic or social condition", and that the right to health is protected by the International Covenant on Economic, Social and Cultural Rights as well as other widely ratified international instruments, including the International Convention on the Elimination of All Forms of Racial Discrimination, the Convention on the Elimination of All Forms of Discrimination against Women, the Convention on the Rights of the Child and the Convention on the Rights of Persons with Disabilities,

Recalling also the 2012 IPU resolution, Access to health as a basic right: The role of parliaments in addressing key challenges to securing the health of women and children, and the 2017 addendum to that resolution, and expressing appreciation for the national and international efforts that have been made to advance the right to health for all,

Underlining that the world's governments have set achieving universal health coverage (UHC) by 2030 as a target of the Sustainable Development Goals (SDGs) (in particular Goal 3, target 8), and welcoming coordination mechanisms such as the Global Action Plan for Healthy Lives and Well-being for All and multi-stakeholder platforms, including UHC2030,

Welcoming the Political Declaration adopted at the seventy-fourth session of the United Nations General Assembly High-Level Meeting on universal health coverage, and recalling important commitments and goals set in the area of Financing for Development for the world's governments in the context of the Addis Ababa Action Agenda,
Acknowledging the important role of parliaments and parliamentarians in advancing the UHC agenda, and the need for meaningful collaboration with public authorities, non-governmental organizations, academic institutions, private sector entities and all relevant stakeholders in order to achieve UHC,

Noting that, although major progress has been made towards UHC, half the world's population still lacks access to necessary health services, that 100 million people are pushed into extreme poverty each year because of health expenses, and that 800 million people spend at least 10 per cent or more of their household budget on health-care expenses,

Noting also that UHC means national health policies and programmes in which all ${ }^{1}$ The delegation of India expressed a reservation on the words "indigenous peoples" in preambular paragraph. ${ }^{8}$

individuals and communities have access to the full spectrum of essential, available, accessible, acceptable, affordable and quality health services, from health promotion to prevention, diagnosis, treatment, rehabilitation and palliative care, at the time of need, which are delivered in a respectful and equitable manner and without causing financial hardship,

Recognizing that UHC must ensure that services are provided on an equal and nondiscriminatory basis and that no one is left behind, in particular the vulnerable, disadvantaged, stigmatized or marginalized, children, youth, women, the elderly, indigenous peoples, people living with disabilities (especially women and children), people with rare or neglected diseases, migrants, refugees, people on the move, rural populations, especially rural women, and people affected by mental health conditions or pre-existing medical conditions, and especially noting that the

${ }^{1}$ The delegation of India expressed a reservation on the words "indigenous peoples" in preambular paragraph 8 . 
impact is compounded when an individual suffers multiple or intersecting forms of discrimination,

Expressing concern that women, children, adolescents, the elderly, and people living with disabilities bear the greatest burden of ill health and preventable deaths, and often have limited financial resources to pay for essential health care, thus placing them at an economic disadvantage and higher risk of poverty,

Noting with concern that women generally bear higher out-of-pocket health-care-related expenses than men, and so are adversely affected by limitations or non-coverage of services under UHC that are unique to women, such as for reproductive and maternal health,

Recognizing that primary health care, including immunization campaigns, is the most inclusive, effective and efficient approach to enhancing people's physical and mental health and well-being, and that such health care is also the cornerstone of a sustainable health system capable of UHC, and welcoming the intergovernmental commitment in the 2018 Declaration of Astana to strengthen primary health-care systems as an essential step towards achieving the SDGs,

Insisting on the importance of people-centred health services that are equitable, well-resourced, accessible, integrated and supported by a skilled workforce, as well as of patient safety and quality health care as core components of health-system governance in order to fully empower people to improve and protect their own health,

Noting the importance of continued commitment and progress towards the implementation of the WHO Global Strategy on Human Resources for Health: Workforce 2030, as well as the implementation of the outcomes of the United Nations High-Level Commission on Health Employment and Economic Growth in supporting human resource requirements as a building block for strong health systems and the foundation for achieving UHC,

Underlining the constitutional dimension of the right to health and the importance of allocating specific percentages and portions of national budgets to health, as a cornerstone to achieving comprehensive sustainable development,

Underlining also that investment in UHC is an investment in human capital that generates jobs, increases growth and reduces inequalities, including gender inequality, and recalling the importance of sustainable, adequate health funding,
Being mindful that progress towards UHC also requires the political, social, economic, environmental and climate determinants of health to be addressed,

Noting that the increasing number of complex emergencies is hindering the achievement of UHC, and that it is vital to ensure coordinated and inclusive approaches through national and international cooperation, following the humanitarian imperative and humanitarian principles to safeguard UHC in emergencies,

Expressing its concern at the increasing number of refugees around the world, taking into account that providing health care for refugees can be a great burden for host countries, some of which are hosting millions of them, and recognizing the responsibility of the international community to take solid steps in providing refugees with UHC,

Conscious of the connection between global health security and UHC, and of the need to continue delivering essential health care in emergency and fragile situations, especially as regards women in armed conflicts, and determined to take action to prevent epidemics and the spread of disease by advocating and supporting countries' compliance with the International Health Regulations (2005) and to ensure their respective strong core capacities in public health to prevent, detect and respond to public health risks, particularly during health emergencies,

Recognizing that the achievement of UHC is intrinsic to achieving healthy lives and well-being for all, at all ages, and that it requires strong and sustained political commitment at all levels,

1. Reaffirms that the devotion of maximum available resources to the progressive realization of UHC is possible and achievable for all countries even in challenging settings, and calls on parliaments and parliamentarians to take all applicable legal and policy measures in order to help their respective governments to achieve UHC by 2030 and to ensure quality, affordable and accessible health care;

2. Urges parliaments to put in place a robust legal framework for UHC, to ensure effective implementation of UHC legislation in reality, and to ensure that the right of everyone to public health and medical care is guaranteed for all in law and in practice, without discrimination; 
3. Also urges States to work closely with their national parliament, supported by the IPU, to raise further awareness among parliaments and parliamentarians about UHC and fully engage them in the process, so as to sustain political support towards achieving UHC by 2030;

4. Further urges parliaments to work for UHC to be established henceforth as a feature of national development plans and policies, health being at once a prerequisite for and a factor in countries' sustainable development;

5. Calls on States to ensure that national health policies and programmes are gendersensitive, results-based and consistent with international human rights standards, including the principles of respect for autonomy and informed consent, and are developed through an inclusive and participatory process, and urges parliaments to remove legal or other barriers preventing access to health services, including by strengthening primary health care and human resources, such as by supporting dual vocational training;

6. Calls for priority to be given to the availability, accessibility, affordability, acceptability and quality of health-care services, including essential services for women, children, adolescents and groups in vulnerable positions, particularly at the primary-health-care level, in particular by promoting policies that acknowledge and support the work of community health providers, most of whom are women, so that they can effectively provide essential health services, especially in rural areas;

7. Encourages States to implement prevention and education programmes to promote the health literacy of their citizens and to address behaviour-related health concerns, such as alcohol and tobacco use, occupational health and safety, obesity and sexually transmitted diseases;

8. Urges States - in order to meet a broad-based request from citizens to be accompanied towards the end of their lives in a dignified and as painless a manner as possible - to include palliative care and pain relief in their basic health-care services;

9. Calls on parliaments to strengthen health systems so as to reduce maternal, newborn, child and adolescent mortality and morbidity by strengthening sexual, reproductive, maternal, newborn and adolescent health and nutrition services, promoting in particular breastfeeding, systematic immunization campaigns and early childhood development interventions, as well as by providing information on and access to the broadest possible range of safe, effective, affordable and acceptable modern methods of family planning;

10. Urges parliaments to ensure that healthsector interventions for protecting sexual and reproductive health and rights, especially for adolescents, are combined with promotive, early detection, preventive and educational measures in other sectors, in particular with respect to promoting gender equality and combating child, early and forced marriage, early and unintended pregnancies, and gender-based violence, including female genital mutilation or other forms of genderbased violence;

11. Also urges parliaments to respond to the specific health needs of women and girls, including awareness, prevention and early detection of cervical cancer, breast cancer and HIV-AIDS; provision of support and services to young girls during puberty; as well as adequate support and services to survivors of gender-based violence;

12. Calls on parliaments to ensure that national policies to implement UHC address malnutrition in all its forms, with special attention to the nutritional needs of adolescent girls, pregnant and lactating women and children during the first 1,000 days;

13. Also calls on parliaments to promote and foster access to essential, affordable, safe, effective and good-quality medicines, medical devices, contraceptives, vaccines, diagnostics and other technologies, without discrimination, to combat counterfeit and falsified medicines, and to support innovation, research and development in medicines and vaccines for communicable and non-communicable diseases;

14. Urges parliaments to promote the immunization programmes of their respective governments, as the most effective preventive measure against infectious diseases, and to enact measures that will tighten patient safety regulations during the clinical testing of new vaccines to allay public fears of vaccination; 
15. Underlines the need for early diagnosis, support, accessible and quality health information and affordable health services for people living with disabilities or chronic physical and mental health conditions, and for efforts to empower and include them to be scaled up;

16. Encourages a partnership-based approach to achieving UHC on a whole-of-government and whole-of-society basis, and invites parliaments to raise public awareness of UHC and engage communities and all relevant stakeholders in the development of plans and strategies that respond to their realities;

17. Underlines the need for a systematic approach to issues of gender, equity and human rights in health budgeting and planning and health-related decision-making processes, the informed participation of individuals and communities, particularly women, and health information systems which generate reliable evidence on health needs to ensure sound policy choices;

18. Urges parliaments to insist on the establishment of robust national indicators and disaggregated data for measuring progress on UHC, and calls for regular reporting and accurate use of disaggregated data to remove gender-based discrimination in the implementation of UHC;

19. Calls on parliaments to consider the Addis Ababa Action Agenda on Financing for Development and to allocate adequate domestic resources for the progressive realization of UHC through sustainable health financing, including through increased budgets where needed, as well as through measures to promote efficiency, equity, quality, cost containment and a stable basis for funding, mindful of the nominal minimum target for domestic resources identified by $\mathrm{WHO}$ as equivalent to 5 per cent of GDP;

20. Urges States to allocate more resources for the recruitment of new doctors and healthcare staff, undertaking positive action in the relevant international forums aimed at easing the overly hard budget constraints implemented during the past decade;

21. Calls on parliaments to ensure that training for human resources is on a par with the reliability of health facilities' equipment in order to bridge the gap sometimes observed between human resources and adequate health infrastructure;
22. Also calls on parliaments to ensure financial protection in order to reduce out-of-pocket payments for health services and to eliminate financial barriers that prevent access to health;

23. Requests parliaments in developed countries providing official development assistance to work towards increasing their country's assistance for health, including for research and development, while reminding developed countries of their commitment according to the United Nations General Assembly Resolution to contribute at least 0.7 percent of their GDI to official development assistance, and urges parliaments to ensure that governments and international funding partners align their financial support with health systems, plans and priorities designed to achieve UHC in recipient countries;

24. Calls on parliaments to use all generic parliamentary functions to hold their respective national governments accountable for the effective implementation of their UHC commitments, monitor the impact of UHC policies and programmes, and encourage governments to take corrective action where necessary, and urges parliaments to establish mechanisms to follow up on the implementation of this resolution;

25. Underlines the transformational potential of technology-based health innovations and new models of health care to accelerate progress towards achieving UHC, especially in low- and middle-income countries;

26. Calls on public authorities, especially health institutions, to observe strict ethical standards of care and, along with other national and international entities, to ensure continued health-care services and treatment for victims of armed conflict, fragile contexts, or health and other emergencies, such as natural disasters;

27. Strongly urges States and all parties to armed conflict to ensure health care and to develop effective measures to prevent and address acts of violence, attacks and threats against medical personnel and humanitarian personnel exclusively engaged in medical duties, their means of transport and equipment, as well as health centres, hospitals and other medical facilities and also schools and training centres in armed 
conflict, in accordance with the Geneva Conventions and their Additional Protocols and United Nations Security Council resolution 2286 on the protection of health care in armed conflict, bearing in mind that such attacks render efforts to build up health systems impossible;

28. Calls on the relevant authorities of the international community to create an effective mechanism for all countries to share the joint responsibility of providing refugees with adequate health services and achieving UHC for refugees wherever possible;

29. Also calls on parliaments to take all possible measures to ensure global health security by preventing the spread of diseases and other public health events, particularly through systematic immunization campaigns, as well as strengthening surveillance and response systems, and to advocate for the implementation of the International Health Regulations (2005) and for the allocation of appropriate resources to meet countries' obligations and address critical gaps in their respective public-health core capacities to prevent, detect and respond to public health risks;

30. Urges that antibiotic resistance be included as a global indicator or an intermediate goal in the SDGs, recognizing that antimicrobial resistance (AMR) is a serious and pressing global health threat and that measures designed to counteract antibiotic resistance are an important aspect of protection against threats to human health and of ensuring access to necessary medicines, calls for full implementation of the Interagency Coordination Group recommendations, and calls on the Tripartite agencies and the United Nations Environment Programme to step up their work on AMR, especially to support countries to implement their national action plans;

31. Also urges parliaments to address the political, social, economic, environmental and climate determinants of health as enablers and prerequisites for sustainable development, and to promote a multisectoral approach to health;

32. Requests parliaments to facilitate and support the learning and sharing of UHC experiences, best practices, challenges and lessons learned across IPU Member Parliaments and their parliamentarians;

33. Also requests the agencies of the United Nations system, in particular WHO, to provide countries with coordinated, multifaceted support aimed at achieving UHC, to collaborate in monitoring the achievement of UHC, considering WHO's mandate to evaluate health indicators, and to boost the capacity of parliaments and parliamentarians to develop and monitor national UHC policies through the establishment of strong, learning health-care systems;

34. Further requests parliaments and parliamentarians to work for States' implementation of the recommendations of the meetings on achieving UHC, particularly those of the United Nations High-Level Meeting on universal health coverage held in September 2019, and calls on the IPU to provide its Members with all the tools required for the follow-up and evaluation of those recommendations. 